\title{
A Fuzzy AHP Approach for Technology Transfer Problems: A Case Study of Africa and China Partnerships
}

\author{
Udochukwu Frank Iroegbu1 ${ }^{*}$, Michael Adadu Ushie ${ }^{2}$, Boniface Paul Otiala ${ }^{2}$ \\ ${ }^{1}$ Huawei Technologies, Lagos, Nigeria \\ ${ }^{2}$ Faculty of Management, University of Cross River State, Calabar, Nigeria \\ Email: ^frankyudj@yahoo.com, ushiemikecy@yahoo.com, paulotiala@gmail.com
}

How to cite this paper: Iroegbu, U. F., Ushie, M. A., \& Otiala, B. P. (2021). A Fuzzy AHP Approach for Technology Transfer Problems: A Case Study of Africa and China Partnerships. American Journal of Industrial and Business Management, 11, 646-663. https://doi.org/10.4236/ajibm.2021.116042

Received: May 12, 2021

Accepted: June 20, 2021

Published: June 23, 2021

Copyright $\odot 2021$ by author(s) and Scientific Research Publishing Inc. This work is licensed under the Creative Commons Attribution International License (CC BY 4.0).

http://creativecommons.org/licenses/by/4.0/

\begin{abstract}
The China-Africa partnership is presently facing certain setbacks, which are likely to affect their relationships if proper measures are not put in place. Hence, this study investigates the challenges affecting technology transfer between the two sides by creating a platform through which reliable solutions can be generated. Using the case study analysis and the Fuzzy AHP approach, several problems are identified in this study, including management and strategic issues, marketing concerns, technical issues, environmental difficulties, and regulatory concerns. From the analysis, the management and strategic problems are ranked the most essential in technology transfer, through marketing issues, technological challenges, environmental issues, and, thus, the regulatory problems. Such ranking helps in prioritizing which problems to address first to attain competitive technology transfer between the two sides. With the knowledge generated from the study, managers and other stakeholders involved in the China-Africa partnership will be able to facilitate the successful business relationship and ensure sustainable growth on a global scale.
\end{abstract}

\section{Keywords}

Technology Transfer, China-Africa Partnership, Fuzzy AHP, Management, Sustainable Development

\section{Introduction}

Technology transfer is one of the recent topics that are increasingly dominating the contemporary studies conducted by individual business organizations, industries, governments, non-governmental organizations, and by scholars from 
different disciplines. With the extent of globalization and modernization, which are associated with advanced technological developments, considering and creating reliable and effective technology transfer between organizations and countries has become an integral part of the global economic growth. Technology transfer has become a beneficial approach through which organizations and governments win competitive leverage over their direct competitors (Kaushik et al., 2014; Shen \& Power, 2017). Weerawardena et al. (2015) and De Jonge (2016) believe that organizations or countries develop their unique ways through which they explore their technological assets towards increasing multi-dimensional growth and profitability. Such technical assets ensure that an organization can innovatively produce products that guarantee market satisfaction, thus maintaining market dominance (Glachant \& Dechezlepretre, 2017).

Similarly, countries with advanced technological assets have proved to dominate the global market, as well as geopolitics. From this perspective, Chatterji believes that the internal exploitation of the technological assets by an institution through planning, perceiving, developing, designing, manufacturing, and marketing has become essential, especially when it comes to technology transfer through external means (Chatterji, 2016). Technology transfer has been adopted by both the developed and developing countries, through which they try to improve their competitive advantage. They can achieve these by acquiring the best technological assets from the best sources to transfer what they have produced to the most reliable market as a way of expanding their market dominance. Technology transfer is currently facing severe challenges as it is yet to receive the necessary policy development in most nations, especially those undergoing an extensive process of development. As noted in a study by Karani, technology transfer may play a crucial role in providing replicable models for the less-developed and developing nations to solve economic, technological, social, and environmental problems and moving such technological and innovative ideas from the sources through production, sales, and marketing act as the main hindrance to the whole process (Karani, 2001; Kirchherr \& Matthews, 2018). Such procedures for transferring technological assets from the technically advanced countries have proved to be highly costly to most of the developing and less developed countries, thus affecting the entire process negatively.

China is one of the leading technologically advanced countries that have invested heavily in transferring innovative ideas and technology to African countries. As noted in a report by Shen and Power, technology transfer has become a priority for a new phase in African-China cooperation. Still, it lacks the right policies and directions to ensure that the less-developed side benefits from the partnership, instead of the other way round (Shen \& Power, 2017). Africa has yet to learn from the booming Chinese economy, particularly the processes it undertook to facilitate scientific and technological development. Such developments can help less-developed and developing African countries to address most of their third world socio-economic, political, and environmental challenges (Urban et al., 2015). Likewise, such underlying issues have not been evaluated by 
researchers who have only concentrated on determining the rate of the technology transfer and its benefits, leaving behind the possible problems that affect the entire process (Tambo et al., 2017).

From this perspective, this research aims to identify the problems and factors affecting technology transfer between China and Africa. Following this, the research problems are as follows:

- What are the factors that negatively affect the transfer of technology between China and Africa?

- Which factor impacts the process more? Which should be prioritized? and

- How do these factors compare to those already identified by existing literature on technology transfer?

The study also seeks to explain and relate empirical and practical aspects of the entire concept to the context of the

China-Africa deals, as well as to generate a priority matrix to gain perspective on which factors impact the process of technology transfer more. To attain this research goal, the study uses a Fuzzy analytical hierarchy process to evaluate the technology transfer problems between Chinese-African partnerships.

From this perspective, this research aims to identify the problems and factors affecting technology transfer between China and Africa. Following the preceding arguments, this study aims to answer the following questions. What are the factors that negatively affect the transfer of technology between China and Africa? Which factor impacts the process more? Which should be prioritized? And, how do these factors compare to those already identified by existing literature on technology transfer? We address these questions by relating to empirical studies and practical aspects of the entire context of the China-Africa deals and generate a priority matrix to gain perspective on which factors impact the process of technology transfer more. Therefore, we apply a Fuzzy analytical hierarchy process to evaluate the technology transfer problems between Chinese-African partnerships to attain the goal of this study. Hence, the following contributions:

\section{Literature Review}

\subsection{Technology Transfer}

Numerous prior scholars note that the rapid advancement in technological developments has led to a massive shortening of the product life cycle. Nowadays, products take a shorter time to produce and are immediately placed within their respective markets. For instance, according to a study by Lee et al. (2010) on the effects of technological development in production, an organization that wants to compete effectively in the global arena has to keep on developing and implementing new technologies that can differentiate it from other competitors. As per the illustration by Karani, technology is simply a complex phenomenon composed of techniques and knowledge, and its transfer from the developed countries to the less developed ones may prove to be impossible without migrating into formal agreements and using procedures that are formally recognized (Tam- 
bo et al., 2017). The scholars further note that most organizations within the modern business setting have realized the benefits associated with the adoption of technologies from the best sources through technology transfer. To meet their pressing challenges towards better and new products, services, processes, and practices to deliver higher effectiveness and efficiency. Kumar affirms this argument by indicating that any inter-regional or inter-organizational technology transfer is a key to innovative business processes, which ensures both organizational business growth and massive economic growth and sustainability within the countries involved (Kumar et al., 2015).

Despite the recognized advantages of technology transfer, Proskuryakova, Meissner, and Rudnik argue that it has also become one of the critical challenges affecting business organizations and the institutions within the global economy. The author's further note that the transfer is a complex process through which technology assets are moved from the sources to the supply chain in an uncontrolled and unbalanced manner, thus undermining the principles of the free market (Proskuryakova et al., 2017). However, as noted by Al-Mabrouk and Soar, recent studies have proven that with proper research, it is possible to address such issues and to turn them into opportunities for sustainable growth (Al-Mabrouk \& Soar, 2009).

\subsection{The Major Contribution to Technology Transfer}

\subsubsection{China-Africa Partnership}

Several studies that clearly illustrate the actual state of China-Africa partnerships have been conducted. The literature shows the emergence of the problems associated with technology transfer. According to Brautigam, as indicated in Figure 1, the China-Africa trade was stable before the year 2014 until it experienced a drastic decline from 2014 onwards. The drop is a result of global issues relating to the fall of global commodity prices (Brautigam, 2018).

In a different study by Sow, following the Forum on China-Africa Cooperation (FOCAC), Chinese collaborations have increased in all regions of the world, not just in Africa. Since 2014, there is a notable increase in Chinese investments in South America, the Middle East, among other regions. Figure 2 illustrates the expansion of Chinese collaborations in different parts of the world, including Africa (Sow, 2018).

\subsubsection{Other Studies}

In the study by Al-Mabrouk and Soar that focused on analyzing major issues affecting information technology transfer within the Arab counties, the findings indicated that the synthesis procedures and the coding approach resulted in a total of ten master issues that cut across different aspects of a successful technology transfer (Al-Mabrouk \& Soar, 2009). In a similar study conducted by Sung, the researcher focused on identifying the main factors that influence technology transfer and their roles in ensuring successful technology transfer within the I.T. industry in Korea. In the findings, the study found out that the Concreteness 


\section{China-Africa Trade}

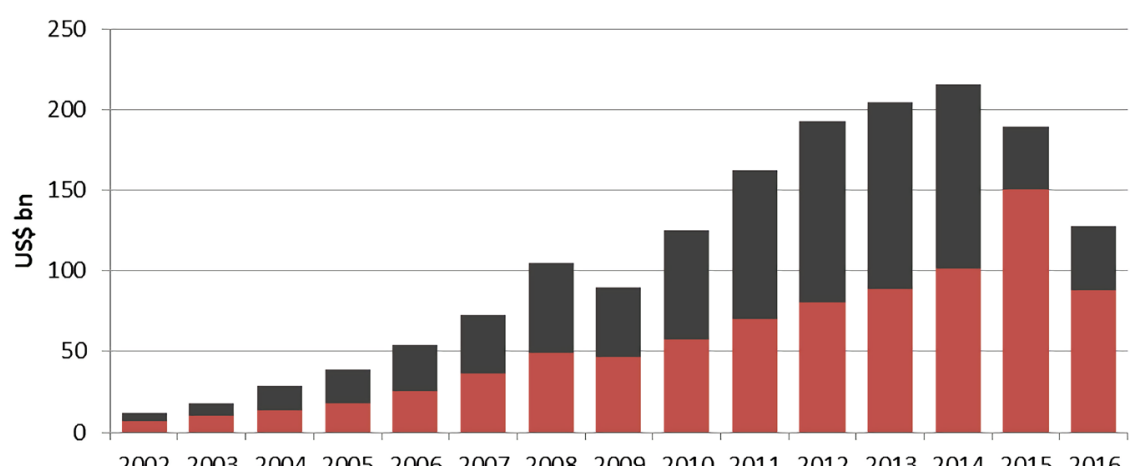

200220032004200520062007200820092010201120122013201420152016

- China Exporting to Africa $\quad$ China Importing from Africa

January 2018

CHINA*AFRICA

Figure 1. China-Africa trade.

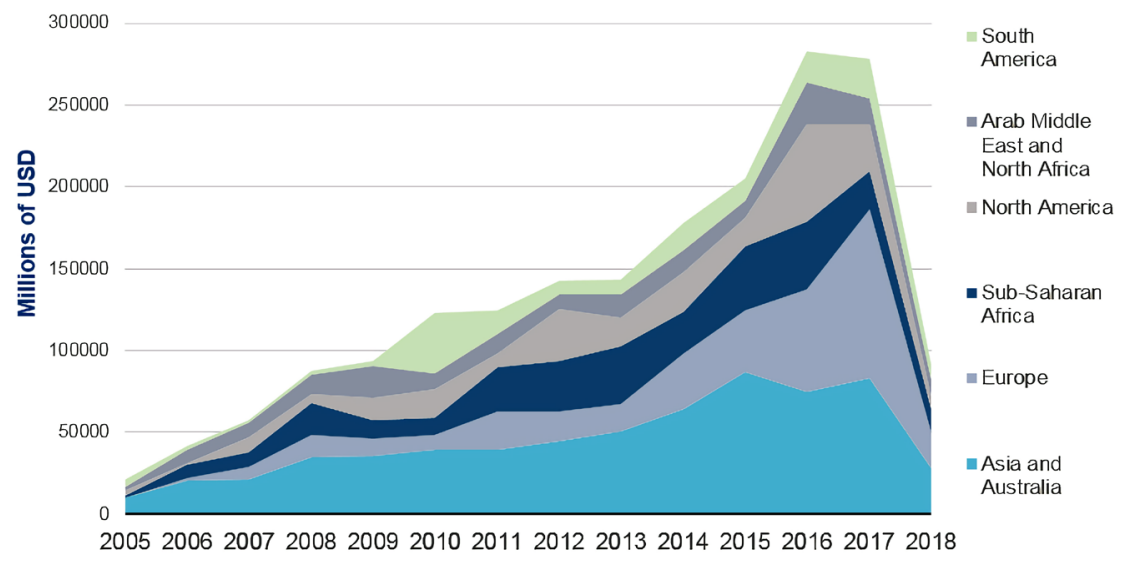

Source: Chinese Investment Tracker, AEI

Figure 2. The Chinese investment tracker.

of Technology is the highest influential factor for any technology transfer within the area of the study. The concreteness of technology in the study is defined as the specificity and definiteness of the technology being transferred. And it is the degree of knowledge that comes with it.

In the Korean context, Sung noted that the use and practical need for the transfer of a specific technology in the recipient country is a major contributing factor for facilitating the exchange. Consequently, the absence of this factor was noted to have been a significant barrier to a successful technology transfer. Following the concreteness of technology, Sung also identified communication channels, collaboration, management, government support, and incentives for transfer as the other important components for an effective technology transfer (Sung, 2009). In another study, some of the critical factors of I.T. performance in Libya's petroleum industry were analyzed and identified (Mohamed et al., 2012). As a 
result, the researchers concluded that technology learning and government support capability are the primary predictors of I.T. performance. While the transfer of I.T. knowledge is one of the primary technology transfer strategies most organizations have adopted, this study contributed significantly to identifying the possible challenges that might affect this process from one country to another (Sung, 2009).

In a different study, Malik and Hattasinghe further analyzed more factors that influence technology transfer. The study identified and analyzed various human resource barriers that act as impediments to smooth and efficient technology transfer. To ensure sufficient data collection and analyses, and to test the main hypotheses, the study took case studies of sixteen international corporations' subsidiaries within Thailand. After analyzing the data, the researchers concluded that the lack of techniques and essential skills act as barriers to technology transfer within the country. As further elaborated by the study on human knowledge and skills on different technological systems and applications of technology, assets help both the organizations and their members to benefit from the technology transfer wherein they absorb more complex knowledge competitively. From this point of view, the authors further indicate that a lack of human resource knowledge and skills on the fundamental technologies makes it hard for them to absorb and benefit from the sophisticated technology being transferred from other advanced sources (Malik \& Hattasingh, 2013). In a different study, Jung et al. (2015) identified some of the failure and success factors of the commercialization of technology within the public R\&D. The researchers also evaluated various barriers that affect the actual commercialization of technology in different industries in Korea. In the findings, cooperation with the developers and market capability were identified as the most significant factors that determine the actual failure or success of the commercialization of technology. On the other hand, the study identified market condition deterioration, insufficient funds, and the insufficiency of marketing capabilities as the most influential barriers towards technology commercialization (Jung et al., 2015).

Kaushik further investigated the real factors that influence technology transfer. They conducted a comprehensive literature review on the background and literary contributions to the field of technology transfer. As a result, several barriers and enablers of the process of technology transfer implementation have been identified (Kaushik et al., 2014). As per the review, it was noted that Leischnig, Geigenmueller, and Lohmann, explored the role of interaction quality and organizational capabilities within inter-organizational technology transfer, especially the one that takes place between different countries or regions. In their findings, the researchers highlighted connections between the important consequences of the interaction quality and antecedents to determine the overall success of the inter-organizational technology transfer process (Leischnig et al., 2014). In a similar literature review by Battistella, De Toni, and Pillon, more factors that determine the failure and success of a technology transfer process were evaluated. The factors ranged from the human resources practices, supply 
chain management strategies, governance, and level of knowledge, among others (Battistella et al., 2016).

\subsection{Study Gap}

While several studies closely look at the process of technology transfer between and among organizations, countries, and regions, there is still a lack of attention and synthesis on the African Experience. The extant literature is mostly an assessment of the experiences of specific countries, such as Korea, Libya, and Thailand. There remains little or no information on the perspective of Africa as a region, and this study attempts to cover this gap. Moreover, of the studies available, only a few have analyzed their research using an AHP framework to generate a priority matrix. Many of the studies proceeded to identify factors that affect technology transfer in respective countries but do not impress on their prioritization and the extent of their impact. Only Sung, who studied the Korean Experience, ranked the factors in terms of priority through regression analysis (Sung, 2009). In response to these identified gaps in the literature, the study attempts to provide a synthesis of the African Experience on technology transfer, as well as generate a priority matrix that will better inform decision-making from all parties involved - from organizations, companies, countries, and entire regions.

\subsection{Theoretical Review}

This study aims to evaluate some of the leading technology transfer problems based on the case study of the China-Africa partnership. Ranking the problems as identified, the Analytical Hierarchy Process (AHP) framework was applied whereby several constructs of technology transfer problems were sorted in an extensive review, then validated based on the opinions from the experts and categorized into some dimensions of the problems (Vaishnavi et al., 2017). From the previous section, several of the factors affecting technology transfer in various countries were concreteness of technology, collaboration among participants, management support, government support, incentives (Sung, 2009; Mohamed et al., 2012; Battistella et al., 2016), technology learning (Mohamed et al., 2012), human resources and inefficiency (Malik \& Hattasingh, 2013; Battistella et al., 2016), lack of technical skills (Jung et al., 2015; Battistella et al., 2016), commercialization of technology, cooperation, and market capability (Leischnig et al., 2014), supply chain management (Battistella et al., 2016).

The results and its categorization were anchored on the abovementioned factors from the systematic review. The experts were chosen based on their familiarity with Chinese-African partnerships, likewise having a notable and substantial work with African and Chinese multinational corporations as consultants. Said specialists also have an expansive and deep knowledge of the context of the respective countries. The dimensions identified are marketing-related problems, relative economic issues, technical problems, managerial and strategic chal- 
lenges, and regulatory problems. The experts involved in the validation of these problems were selected from a combination of Chinese and African multinational companies.

\section{Methodology}

This study is an empirical, mathematical, and quantitative research paper, which applies a quantitative methodology to collect data, analyze and identify possible problems affecting technology transfer between China and Africa. The study used a case analysis approach to understand the actual problems affecting technology transfer between China and Africa. The cases analyzed are those involving the China-Africa partnership, especially in economic, political, and social developments. The sourced data was then categorized into five dimensions using experts' input, then ranked using the Analytical Hierarchy Process (AHP). The AHP framework for evaluating technology transfer problems is structured into three levels. The first level includes prioritizing the technology transfer problems, the second level comprises the five dimensions of the problems of the technology transfer, and the final level highlights the constructs under each dimension. The following Figure 3 is a clear demonstration of the AHP methodology used in highlighting the main problems affecting technology transfer.

\subsection{An Illustration of the AHP Research Technique}

AHP technique is used mainly to compare the alternatives with references to certain criteria, using a pairwise technique, which then results in a final comparison matrix that may be used to evaluate how alternative solutions are ranked for effective decision making (Bali \& Amin, 2017). AHP technique involves three main steps starting with an establishment of structure with elements of decision making, then an establishment of the comparison matrices for the construct pair, and finally, the actual calculation of the consistency using two main equations. The equations are:

$$
\mathrm{CI}=\left(\lambda_{\max }-n\right) /(n-1)
$$

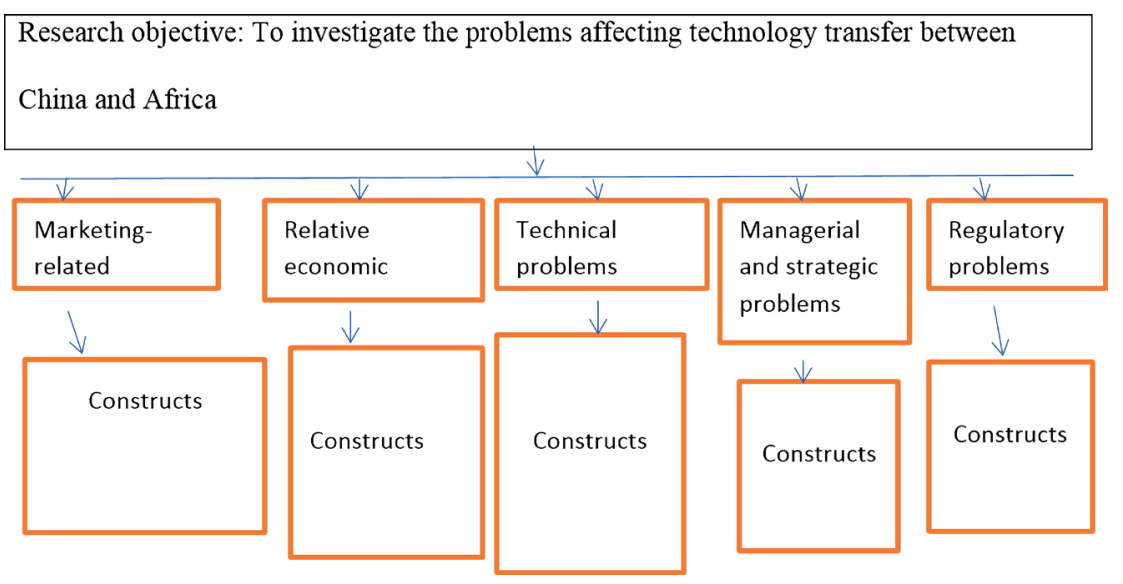

Figure 3. AHP framework. 


$$
\mathrm{CI}=\mathrm{CI} / \mathrm{RI}
$$

The size matrix determines the R.I. value while the consistency ratio (C.R.) range changes as per the matrix size. The matrix size is 0.05 for the matrix of $3 \times$ 3 for the $4 \times 4$. The AHP framework was utilized for this study because it can objectively evaluate projects and partnerships based on standard criteria. The results can better inform future decision-making processes about the effective transfer of technology from developed countries to their less developed counterparts.

\subsection{Data Analysis and Results}

\subsubsection{Research Variables}

In this study, there are two sets of variables: independent and dependent variables. The independent variables do not depend on the variation of other factors. Particularly for this study, these are management and strategic factors, market-related issues, technical concerns, economic problems, and regulatory issues. The dependent variable is the technology transfer within the China-Africa partnership.

\subsubsection{Data Analysis}

AHP technique is used to analyze the relationship between the variables, thus coming up with reliable answers to the research question. Following the experts' input ratings, matrices were developed, and calculations were made to obtain specific priorities of the problems using the AHP technique. The AHP framework for the investigation of the actual problems facing technology transfer is structured hierarchically, including three primary levels. The levels are the goal, which is to evaluate the problems affecting technology transfer between China and Africa. The identification of the five dimensions of the problems, including marketing-related problems (M.P.), relative economic problems (E.P.), technical problems (T.P.), managerial and strategic problems (M \& SP), and regulatory problems (R.P.). The constructs of each dimension are determined at the third level. Based on the research question, which is to identify the problems affecting technology transfer between China and Africa, this study identifies the dimensions of the problems as well as their constructs as shown in Table 1 below.

Table 1. Pairwise comparison matrix for the problem dimensions.

\begin{tabular}{cccccccc}
\hline Criteria & MP & EP & TP & M \& SP & RP & PRIORITY MATRIX & RANK \\
\hline MP & 1 & 2 & 2 & $1 / 3$ & 2 & 0.19505 & $2^{\text {nd }}$ \\
EP & & 1 & 1 & $1 / 5$ & 1 & 0.10065 & $4^{\text {th }}$ \\
TP & & & 1 & $1 / 3$ & 3 & 0.14384 & 3 rd \\
M\&SP & & & & 1 & 6 & 0.48159 & $1^{\text {st }}$ \\
RP & & & & 1 & 0.07886 & $5^{\text {th }}$ \\
$\mathrm{CI}=0.0346494$ & & & & & & &
\end{tabular}

Maximum Eigen Value $=5.1386$ 


\subsubsection{The Problem Dimensions}

From the results analyzed in Table 1 above, it is clear that managerial and strategic problems were the most important dimension concerning problems affecting technology transfer, with a priority matrix of 0.48159 . Next is the marketing-related problem with a matrix of 0.19505 . Technical problems marked the third most important dimension, followed by relative environmental problems with matrices of 0.14384 and 0.10065 , respectively. The least important dimension was regulatory problems with a matrix of 0.07886 . These, therefore, indicates that even though all the identified dimensions seem to be essential in the technology transfer within the Chinese-African context, the one with the highest impact is the managerial and strategic problems. It is indicative that a successful and effective technology transfer requires reliable and efficient management from both the source and the recipient. Given that the AHP framework seeks to inform decision-making processes, the results show that more attention should be given to improving managerial and strategic problems.

The next to be addressed is the marketing-related factors, including market conditions and market capability. Others include technical problems, relative environmental problems, and, finally, the regulatory problems. The priority matrix was likewise given to the experts. The ranking they generated through a survey was consistent with the results of the AHP technique. They noted that the capacity and skill of the receiving country, as well as the market, remain as the primary factor that can hinder or facilitate the success of technology transfer.

\subsubsection{Constructs of Dimensions}

S.I. stands for strategic implication, P.R. personal resources, T.D. training and development support, and CM commitment. As shown in Table 2, they are all constructs of managerial and strategic issues affecting technology transfer.

In Table 3, GA stands for government authorities, E.C. stands for environmental concerns and I.B. for international bodies. I.B. is the highly ranked construct followed by G.A. and lastly, E.C.

Base on the data in Table 4 below, R.L. (reliability) is the most important construct followed by trial-ability (T.A.), then function-ability (F.S.), observe-ability (O.B.), then local sustainability of technology (L.S.), then compatibility (C.P.), the technological ability of suppliers (T.S.), and finally scientific changes (S.C.).

As shown in Table 5, Market requirements (M.R.) and end-user support (E.U.) are the most important constructs, followed by judgment about timing (J.T.), the competition (C.T.), then new area penetration (P.A.), and lastly, more application by existing customers (M.U.). According to the data in Table 6, high-profit margins (H.M.) are the most important construct followed by expected sales inclement (E.S.) and, lastly, the cost-effectiveness (C.E.).

The said constructs were identified after inputs from experts, the result of the case studies, and the following results from the available literature on the subject matter. 
Table 2. Pairwise comparison matrix (PWCM) for managerial and strategic problem.

\begin{tabular}{ccccccc}
\hline Constructs under M \& S & SI & PR & TD & CM & PRIORITY MATRIX & RANK \\
\hline SI & 1 & $1 / 2$ & $1 / 2$ & $1 / 4$ & 0.10518 & 4 th \\
PR & & 1 & $1 / 2$ & $1 / 2$ & 0.18181 & 3 rd \\
TD & & & 1 & $1 / 3$ & 0.23517 & 2 nd \\
CM & & & & 1 & 0.47784 & 1 st \\
\hline
\end{tabular}

Maximum Eigen value $=4.11794$; C.I. $=0.0393141$.

Table 3. PWCM of regulatory problems.

\begin{tabular}{cccccc}
\hline $\begin{array}{c}\text { Constructs under } \\
\text { regulatory problems }\end{array}$ & GA & EC & IB & Priority matrix & Rank \\
\hline GA & 1 & 1 & $1 / 2$ & 0.24022 & 2rd \\
EC & 1 & $1 / 3$ & 0.20984 & \\
IB & & 1 & 0.54994 & \\
\hline
\end{tabular}

Maximum Eigen Value = 3.01829; C.I. $=0.00914735$.

Table 4. PWCM of the dimension of technical problems.

\begin{tabular}{|c|c|c|c|c|c|c|c|c|c|c|}
\hline Constructs under TP & SC & TS & LS & $\mathrm{CP}$ & FS & RL & TA & OB & Priority Matrix & Rank \\
\hline SC & 1 & 1 & $1 / 2$ & $1 / 4$ & $1 / 3$ & $1 / 3$ & $1 / 2$ & $1 / 2$ & 0.05843 & $8^{\text {th }}$ \\
\hline TS & & 1 & 1 & 1 & 1 & $1 / 3$ & $1 / 2$ & $1 / 2$ & 0.08598 & $7^{\text {th }}$ \\
\hline LS & & & 1 & 2 & 1 & $1 / 2$ & 1 & 1 & 0.12515 & $5^{\text {th }}$ \\
\hline $\mathrm{CP}$ & & & & 1 & $1 / 2$ & $1 / 2$ & $1 / 2$ & $1 / 2$ & 0.09505 & $6^{\text {th }}$ \\
\hline FS & & & & & 1 & 1 & 1 & 1 & 0.14490 & $3^{\text {rd }}$ \\
\hline RL & & & & & & 1 & 2 & 2 & 0.21353 & $1^{\text {st }}$ \\
\hline TA & & & & & & & 1 & 2 & 0.15054 & $2^{\text {nd }}$ \\
\hline $\mathrm{OB}$ & & & & & & & & 1 & 0.12643 & $4^{\text {th }}$ \\
\hline
\end{tabular}

Maximum Eigen Value $=8.36405 ;$ C.I $=0.0520074$

Table 5. PWCM of marketing-related problems.

\begin{tabular}{ccccccccc}
\hline $\begin{array}{c}\text { Constructs under } \\
\text { marketing-related problems }\end{array}$ & PA & MU & EU & MR & CT & JT & $\begin{array}{c}\text { Priority } \\
\text { Matrix }\end{array}$ & Rank \\
\hline PA & 1 & 2 & $1 / 5$ & $1 / 5$ & $1 / 2$ & 1 & 0.09656 & 4 th \\
MU & & 1 & $1 / 2$ & $1 / 2$ & $1 / 2$ & $1 / 4$ & 0.07617 & 5 th \\
EU & & 1 & 1 & 1 & 1 & 0.22715 & 1 st \\
MR & & & 1 & 1 & 1 & 0.22715 & 1 st \\
CT & & & & 1 & 1 & 0.18216 & $3 \mathrm{rd}$ \\
JT & & & & & & & & \\
\hline
\end{tabular}

Maximum Eigen Value $=6.43807 ;$ C.I. $=0.0876146$.

\subsection{Application of Fuzzy Triangular Scale for Decision Making}

In Table 7 and Table 8, decision-makers can use the following FUZZY linguistics 
Table 6. PWCM of regulatory problems (RP).

\begin{tabular}{cccccc}
\hline Constructs under RA & CE & HM & ES & Priority Matrix & Rank \\
\hline CE & 1 & $1 / 2$ & $1 / 4$ & 0.14937 & 3 rd \\
HM & 1 & 2 & 0.47423 & 1 st \\
ES & & & 1 & 0.37639 & 2 nd \\
\hline
\end{tabular}

Maximum Eigen Value $=3.21736$; C.I. $=0.108681$.

Table 7. Triangular fuzzy numbers scale.

\begin{tabular}{lcc}
\hline \multicolumn{1}{c}{ Linguistic } & Triangular Fuzzy Number & Reciprocal \\
\hline $\begin{array}{l}\text { Same comparison (equal) } \\
\text { Midline (intermediate) }\end{array}$ & $(1,1,1)$ & $(1,1,1)$ \\
$\begin{array}{l}\text { One element is important enough than the others } \\
\text { (moderately) }\end{array}$ & $(1,3 / 2,1,3 / 2)$ & $(2 / 3,1,2)$ \\
$\begin{array}{l}\text { Midline (intermediate) } \\
\text { One element is strong enough than the others (strongly) }\end{array}$ & $(3 / 2,2,5 / 2)$ & $(2 / 5,1,2 / 3)$ \\
$\begin{array}{l}\text { Midline (intermediate) } \\
\begin{array}{l}\text { One element is stronger in an important aspect than the } \\
\text { others (very absolute) }\end{array}\end{array}$ & $(5 / 2,3,3 / 2,3)$ & $(1 / 3,2 / 5,1 / 2)$ \\
$\begin{array}{l}\text { Midline (intermediate) } \\
\begin{array}{l}\text { One element is absolutely stronger than the others } \\
\text { (extremely absolute) }\end{array}\end{array}$ & $(2 / 7,1 / 2,4)$ & $(1 / 4,2 / 7,1 / 3)$ \\
\hline
\end{tabular}

Table 8. Application of the fuzzy triangular scale.

\begin{tabular}{cccccc}
\hline CRETERIA & MP & EP & TP & M\&SP & RP \\
\hline MP & $1,1,1$ & $1 / 2,2 / 3,1$ & $1 / 4,2 / 7,1 / 3$ & $1,1,1$ & $2 / 9,1 / 4,2 / 7$ \\
EP & $1,3 / 2,2$ & $1,1,1$ & $1 / 3,2 / 5,1 / 2$ & $2 / 3,1,2$ & $2 / 3,1,2$ \\
TP & $3,7 / 2,4$ & $2,5 / 2,3$ & $1,1,1$ & $1 / 2,2 / 3,1$ & $2 / 3,1,2$ \\
M \& SP & $1,1,1$ & $1 / 2,1,3 / 2$ & $1,3 / 2,2$ & $1,1,1$ & $2 / 9,2 / 9,1 / 4$ \\
RP & $7 / 2,4,9 / 2$ & $1 / 2,1,3 / 2$ & $1 / 2,1,3 / 2$ & $4,9 / 2,9 / 2$ & $1,1,1$ \\
\hline
\end{tabular}

terms in prioritizing the problem dimension affecting technology transfer. These linguistics terms may be "small," "Average," "Large," or as explained in a particular context.

\section{Discussion}

Based on the literature review and the findings from this study, it is clear that various problems are associated with the technology transfer between China and Africa, ranging from the capacity of receiving companies to the overall market and government context. Due to the differences in the economic and technological development of both countries, there have been several problems linked to this imbalance. These is confirmed in our findings, illustrating that the main 
problem dimensions include management and strategic issues, regulatory issues, environmental concerns, technique issues related to the manner at which each region has acquired technical skills, and marketing related issues (Karani, 2001). These dimensions are particularly salient in a less-developed region like Africa because it is normally fraught with layers of corruption, inefficiency, lack of strong political leadership, and a dependent economy (Nduku \& Tenamwenye, 2014).

As noted by Chen, following the differences in organizational cultures between the Chinese and African multinational companies, the manner at which they acquire new technologies and manage them to ensure better organizational performance is quite different (Chen et al., 2016). Such differences become major challenges during the technology transfer between the two sides. For instance, Chinese companies are believed to be aggressive in developing and strategically utilizing new technologies in their operation compared to African companies (Chen et al., 2016). Such differences, as illustrated in the literature, therefore, explain the findings in this study, which note that managerial and strategic issues have become major concerns when it comes to the technology transfer between China and Africa.

Additionally, as noted in the study's findings, various marketing-related problems have been marked as the most significant issues affecting technology transfer between China and Africa. This finding is likewise affirmed by the study of Jung, Lee, and Lee, which notes that factors like end-user support, marketing requirements, market-related forces, and benefits. Others, such as competition and consumer behaviors, heavily influence and determine the way that technological assets are transferred within the market. The fact that these factors vary between China and Africa. It thus explains the cause and the nature of the problem (Jung et al., 2015). For instance, Chinese consumers have different preferences for technology from African consumers. Therefore, transferring technological assets that are more preferred in China to Africa does not mean immediate success, as barriers include market capacity, skills that match the entry of technology, and the demand for the said technology (Mohan, 2016). As per the results, technical problems, such as lack of technical skills and know-how, have been identified as a significant problem affecting technology transfer between China and Africa. As noted by Lee, the Chinese people are far ahead of the Africans when it comes to $R \& D$, as well as other significant technological knowledge development. Such differences thus explain the current technical problems affecting the technology transfer between the two regions (Lee, 2018). This gap is the result of the consistent non-prioritization of research and technology development in many countries in the region. It is evidenced by the low budget allocated for R\&D (Soete et al., 2019).

Moreover, the study findings have also identified environmental problems as another major problem affecting technology transfer. As explained, the effort to maintain a green policy has become a significant issue when organizations are trying to acquire new technologies. It is becoming a challenge to adopt new 
technologies and, at the same time, ensure social, economic, and ecologically sustainable development (Leischnig et al., 2014; Lee, 2018). Lastly, there are many regulations between China and African nations that affect the process of technology transfer, including requirements within the bureaucracy, papers, taxes, and other processes that are not done efficiently (Zhang, 2019). Even though this is not a major problem, it still has several implications when it comes to technology transfer. To contrast it with the Korean Experience, as studied by Sung, as show below in Table 9 used regression analysis to rank problems affecting technology transfer in Korea, the table below shows a comparison.

As seen in the table above, there is a stark difference between factors affecting technology transfer when the recipient country is likewise a developed nation. Unlike the African Experience, where leadership, market instability, and lack of technological skill remain prevalent, more advanced nations like Korea tend to be heavily influenced by efficiency and level of support. For Africa, as seen in the case study of China-Africa partnerships, the problems are concentrated on leadership, skill, and market capability. Again, these are the result of the non-prioritization of research and development of technology in the region. Layers of corruption and weak leadership in both the public and private sectors are other factors. The AHP framework was utilized to rank the problem dimensions in the transfer of technology between China and African nations. As seen in Table 7, the results show that the priority of companies and African countries should be focused on resolving managerial and strategic problems, market-related problems and technical problems, as among the top three areas of concern. The priority matrix generated from this study will better inform companies and technocrats in managing and directing their strategies for technological development.

\subsection{Practical and Managerial Implications}

The primary goal of this study was to identify some of the major problems affecting technology transfer between China and Africa to determine the best strategies to employ to avoid such problems in the future. There are different implications of this study, especially when it comes to the management and practical aspects of the process of technology transfer. For instance, with the

Table 9. Comparison of the technology transfer problems identified in Korea and Africa.

\begin{tabular}{cc}
\hline $\begin{array}{c}\text { Problems in technology transfer: } \\
\text { Korean Experience }\end{array}$ & $\begin{array}{c}\text { Problems in technology transfer: } \\
\text { African Experience }\end{array}$ \\
\hline $\begin{array}{c}\text { Concreteness of Technology } \\
\text { Communication Channels }\end{array}$ & $\begin{array}{c}\text { Managerial and Strategic Problems } \\
\text { Collaboration }\end{array}$ \\
Management Support & Market-related Problems \\
Government Support & Tenvironmental Problems \\
\end{tabular}

Source: Sung (2009). 
knowledge gathered from the study on the nature and the degree of the problems, managers or stakeholders will be able to identify which problem dimension has the most significant impacts on the technology transfer, thus prioritizing it when trying to improve the overall outcomes of the transfer. For instance, it will be easy for the managers first to address the issues related to managerial and strategic approaches as well those related to marketing concerns before considering regulatory issues. Such prioritization will ensure effective and efficient problem-solving within the technology transfer process, thus improving the China-Africa partnership (Kirchherr \& Urban, 2018). The results will also help in enhancing the action plan in the future technology transfer processes, including setting up systems that will improve the role performance and performance measures of receiving countries. All these will ensure better results when it comes to the China-Africa development partnership, which is currently facing tough challenges. Furthermore, the priority matrix generated from this study can be used to mitigate additional concerns. If, from the onset, the research has already identified regulatory problems as a rising and potential issue, then companies and institutions can better manage and plan their response. These provide African nations with advanced tools so they can respond to current and potential risks in terms of technology transfer.

\subsection{The Particularity of the China-Africa Experience}

While there are similarities in the available literature about the experiences of various countries such as Korea, Libya, and Thailand, there are particularities in the China-Africa experience. Similarities include the priority of market-related factors and the effectiveness of a technology transfer between countries, as well as the human resource component. However, the distinct Experience of the China-Africa experience based on the case studies, the AHP framework, and the insights of experts are mainly concentrated on the receiving end. This means that African counterparts-whether countries, companies, or organizations have problem areas that lead to the failure or difficulties in technology transfer. As already mentioned in our findings, the management and strategy of recipient bodies are the main problems. While the market-related issues are a constant concern among all countries, this particularly refers to the capacity of the African market to absorb and capitalize on the technology to be transferred, which is related to the third problem on the lack of technical skills. The inclusion of environmental problems is also a unique factor in the African context. Most countries no longer consider this as a priority, or even a potential problem; however, given that the African landscape is prone to several incidents and cases of environmental degradation caused by technological advancement, this is unsurprisingly included as a major challenge. The regulatory issues are likewise expected, given that alongside the managerial and strategic concerns, there have been consistent problems arising from the public and private sector's leadership and transparency. 


\section{Conclusion}

Technology transfer has been identified as one of the best approaches that ensure high utility for attaining competitive advantage within the highly competitive modern market. By identifying the problems that affect technology transfer between China and Africa, this study creates insights into how organizations and governments can create a competitive advantage within the global market. For instance, as noted in the study, by identifying problem areas such as the managerial and strategic, marketing-related, technical, environmental, and regulatory issues faced by both organizations and governments, both sides are better equipped to formulate apt and effective solutions. Moreover, the priority matrix generated in the study can inform organizations and governments on what issue needs their immediate attention. These contribute to creating a successful sharing of technological assets and know-how between parties, thus collectively attaining sustainable growth. China, as the developed side, will be able to facilitate the sustainable development of the African economies through transferring the right technologies. With the knowledge gained in this study, it will further be possible for the continuous strengthening of the China-Africa partnership.

\section{Conflicts of Interest}

The authors declare no conflicts of interest regarding the publication of this paper.

\section{References}

Al-Mabrouk, K., \& Soar, J. (2009). An Analysis of the Major Issues for Successful Information Technology Transfer in Arab Countries. Journal of Enterprise Information Management, 22, 504-522. https://doi.org/10.1108/17410390910993518

Bali, S., \& Amin, S. S. (2017). An Analytical Framework for Supplier Evaluation and Selection: A Multi-Criteria Decision-Making Approach. International Journal of Advanced Operations Management, 9, 57-72. https://doi.org/10.1504/IJAOM.2017.085632

Battistella, C., De Toni, A. F., \& Pillon, R. (2016). Inter-Organisational Technology/ Knowledge Transfer: A Framework from the Critical Literature Review. The Journal of Technology Transfer, 41, 1195-1234. https://doi.org/10.1007/s10961-015-9418-7

Brautigam, D. (2018). Guest Post-Year of the Dogs? A New Boom and Bust for Chinese Construction in Africa. http://www.chinaafricarealstory.com/

Chatterji, M. (Ed.). (2016). Technology Transfer in Developing Countries. Berlin: Springer.

Chen, Y., Sun, I. Y., Ukaejiofo, R. U., Tang, X., \& Brautigam, D. (2016). Learning from China? Manufacturing, Investment, and Technology Transfer in Nigeria. IFPRI Discussion Paper No. 1565, Washington DC: International Food Policy Research Institute.

De Jonge, A. (2016). Australia-China-Africa Investment Partnerships: A New Frontier for Triangular Cooperation? Critical Perspectives on International Business, 12, 61-82. https://doi.org/10.1108/cpoib-01-2014-0003

Glachant, M., \& Dechezlepretre, A. (2017). What Role for Climate Negotiations on Technology Transfer? Climate Policy, 17, 962-981.

https://doi.org/10.1080/14693062.2016.1222257 
Jung, M., Lee, Y. B., \& Lee, H. (2015). Classifying and Prioritizing the Success and Failure Factors of Technology Commercialization of Public R\&D in South Korea: Using Classification tree Analysis. The Journal of Technology Transfer, 40, 877-898. https://doi.org/10.1007/s10961-014-9376-5

Karani, P. (2001). Constraints for Activities Implemented Jointly (AIJ) Technology Transfer in Africa. Renewable Energy, 22, 229-234. https://doi.org/10.1016/S0960-1481(00)00032-X

Kaushik, A., Kumar, S., Luthra, S., \& Haleem, A. (2014). Technology Transfer: Enablers and Barriers-A Review. International Journal of Technology, Policy, and Management, 14, 133-159. https://doi.org/10.1504/IJTPM.2014.060152

Kirchherr, J., \& Matthews, N. (2018). Technology Transfer in the Hydropower Industry: An Analysis of Chinese Dam Developers' Undertakings in Europe and Latin America. Energy Policy, 113, 546-558. https://doi.org/10.1016/j.enpol.2017.11.043

Kirchherr, J., \& Urban, F. (2018). Technology Transfer and Cooperation for Low Carbon Energy Technology: Analyzing 30 Years of Scholarship and Proposing a Research Agenda. Energy policy, 119, 600-609. https://doi.org/10.1016/j.enpol.2018.05.001

Kumar, S., Luthra, S., \& Haleem, A. (2015). Benchmarking Supply Chains by Analyzing Technology Transfer Critical Barriers Using AHP Approach. Benchmarking: An International Journal, 22, 538-558. https://doi.org/10.1108/BIJ-05-2014-0040

Lee, A. H., Wang, W. M., \& Lin, T. Y. (2010). An Evaluation Framework for Technology Transfer of New Equipment in the High Technology Industry. Technological Forecasting and Social Change, 77, 135-150. https://doi.org/10.1016/j.techfore.2009.06.002

Lee, C. K. (2018). The Specter of Global China: Politics, Labor, and Foreign Investment in Africa. Chicago, IL: University of Chicago Press. https://doi.org/10.7208/chicago/9780226340975.001.0001

Leischnig, A., Geigenmueller, A., \& Lohmann, S. (2014). On the Role of Alliance Management Capability, Organizational Compatibility, and Interaction Quality in Interorganizational Technology Transfer. Journal of Business Research, 67, 1049-1057. https://doi.org/10.1016/j.jbusres.2013.06.007

Malik, K., \& Hattasingh, T. (2013). International Technology Transfer Human Resource Issues for the Technology Recipient. In International Society for Professional Innovation Management Conference Proceedings (pp. 1). International Society for Professional Innovation Management (ISPIM).

Mohamed, A. S., Sapuan, S. M., Ahmad, M. M., Hamouda, A. M. S., \& Hang Tuah Bin Baharudin, B. T. (2012). Modeling the Technology Transfer Process in the Petroleum Industry: Evidence from Libya. Mathematical and Computer Modelling, 55, 451-470. https://doi.org/10.1016/j.mcm.2011.08.025

Mohan, G. (2016). Beyond Resources Dependency in Africa? Developing Linkages for Industrialization. In L. Calabrese (Ed.), China-Africa: A Maturing Relationship (pp. 2023).

Nduku, E., \& Tenamwenye, J. (Eds.) (2014). Corruption in Africa: A Threat to Justice and Sustainable Government. Switzerland: Globethics Focus, Globethics International Secretariat.

Proskuryakova, L., Meissner, D., \& Rudnik, P. (2017). The Use of Technology Platforms as a Policy Tool to Address Research Challenges and Technology Transfer. The Journal of Technology Transfer, 42, 206-227. https://doi.org/10.1007/s10961-014-9373-8

Shen, W., \& Power, M. (2017). Africa and the Export of China's Clean Energy Revolution. Third World Quarterly, 38, 678-697. https://doi.org/10.1080/01436597.2016.1199262

Soete, L., Schneegans, S., Erocal, D., Angathevar, B., \& Rasiah, R. (2019). Focus on Sub- 
Saharan Africa. In UNESCO Science Report (pp 482-531). Switzerland: United Nations Educational, Scientific and Cultural Organization.

Sow, M. (2018). Africa in Focus: Figures of the Week: Chinese Investment in Africa. https://www.brookings.edu/blog/africa-in-focus/2018/09/06/figures-of-the-week-chine se-investment-in-africa/

Sung, T. K. (2009). Technology Transfer in the I.T. Industry: A Korean Perspective. Technological Forecasting and Social Change, 76, 700-708.

https://doi.org/10.1016/j.techfore.2008.03.011

Tambo, E., Tang, S., Ai, L., \& Zhou, X. N. (2017). The Value of China-Africa Health Development Initiatives in Strengthening “One Health” Strategy. Global Health Journal, 1, 33-46. https://doi.org/10.1016/S2414-6447(19)30062-4

Urban, F., Siciliano, G., Sour, K., Lonn, P. D., Tan-Mullins, M., \& Mang, G. (2015). South-South Technology Transfer of Low-Carbon Innovation: Large Chinese Hydropower Dams in Cambodia. Sustainable Development, 23, 232-244. https://doi.org/10.1002/sd.1590

Vaishnavi, B., Yarrakula, K., Karthikeyan, J., \& Thirumalai, C. (2017). An Assessment Framework for Precipitation Decision Making Using AHP. 2017 11th International Conference on Intelligent Systems and Control (ISCO), Coimbatore, 5-6 January 2017, 418421. https://doi.org/10.1109/ISCO.2017.7856030

Weerawardena, J., Mort, G. S., Salunke, S., Knight, G., \& Liesch, P. W. (2015). The Role of the Market Sub-System and the Socio-Technical Sub-System in Innovation and Firm Performance: A Dynamic Capabilities Approach. Journal of the Academy of Marketing Science, 43, 221-239. https://doi.org/10.1007/s11747-014-0382-9

Zhang, Y. (2019). Technology and Knowledge Transfer: A Case Study of China's Agricultural Technology Demonstration Center in the United Republic of Tanzania. In M. Huang, X. Xu, \& X. Mao (Eds.), South-South Cooperation and Chinese Foreign Aid (pp. 113-125). Singapore: Palgrave Macmillan.

https://doi.org/10.1007/978-981-13-2002-6 8 